\title{
Compendium of current ceramic materials used for the CAD/CAM dentistry.
}

\author{
Kristýna Hynkovái,2, Iva Voborná2 ${ }^{2}$ Bernard Linke ${ }^{1}$, Liran Levin ${ }^{1}$ \\ ${ }^{1}$ School of Dentistry, University of Alberta, Canada \\ ${ }^{2}$ Faculty of Medicine and Dentistry, Palacky University, Olomouc, Czech Republic
}

\begin{abstract}
Nowadays, patients require the highest quality of treatment, but generally prefer to spend as little time as possible in the dental chair. Therefore, there is significant benefit for using new technologies such as CAD/CAM (computer aided design/computer aided manufacturing), which provides both quality and speed. There is an increase in ceramic materials and ceramic blocks/discs available, with varying properties. This has resulted in some confusion and difficulty in making an informed decision about which material is best for a specific clinical situation. The objective of this review is to provide an overview and comparison of basic mechanical properties of currently used CAD/CAM ceramic materials based on a review of the currently available literature.
\end{abstract}

Keywords: Dental ceramics, CAD/CAM, mechanical properties

\section{Introduction}

Today's patients often prefer whiter teeth and a smile with a straight alignment in a minimum amount of time [1,2]. As a result, the dental practitioner has to determine the right ceramic material with the appropriate optical properties in order to provide a result that the patient finds aesthetically pleasing while simultaneously meeting the requirement of strength and longevity. Knowledge of the different ceramic materials and their varying optical and mechanical properties are thus essential for a dental practitioner, in order that they can determine the best material for the varying clinical situations.

Ceramics are mostly composed of two phases: crystals and glass matrix. The crystals and glass ratio determines the mechanical and optical properties of the ceramics [3].

This paper provides an overview of some of the commonly used CAD/CAM ceramic blocks used for dental restorations based on a review of the currently available literature. The focus will be on the material composition and mechanical properties. The range of the mechanical properties such as flexural strength, elastic modulus and fracture toughness are presented as well.

Basic description of mechanical properties

Mechanical properties describe physical properties of materials exhibits under an applied load.
Flexural strength: Flexural strength is the maximum stress when the material is exposed to flexural loading. To measure flexural strength, common method is to use the three point bending test (uniaxial measurement) or ball on ring configuration (biaxial measurement) [4,5]. Its clinical importance is that it relates to how well the material can withstand chewing force. This is an ideal stage which is not including fatigue of the material. This value can help dentist to decide which material is better for anterior or posterior region, since the chewing forces in the posterior area are generally higher [4].

Elastic modulus: The Elastic or Young's modulus describes the elasticity of the material. It is calculated as the stress strain ratio based on the linear part of stress strain curve. Clinical relevance for dentist is that it describes stiffness of the material [4].

Fracture toughness: Fracture toughness is the energy need for failure of the material. Brittle material such as ceramics have low fracture toughness [4]. To measure the fracture toughness of brittle material, one usually uses single-edge- $\mathrm{V}$-notched beam test (bending method) or indentation strength/fracture method [6]. Clinical importance is that it describes how well the material can withstand the critical propagation of flaws under the applied load [5]. 
Every material of a dental restoration should mimic the mechanical properties of the replaced tissue. Thus, the mechanical properties of ceramics should be ideally close to enamel and dentin. Enamel grinds food, thus its abrasion resistance is important. The hardness value should be prioritized for enamel. Dentin absorbs bite forces, thus strength and elastic modulus should be prioritized there [7].

\section{CAD/CAM ceramics}

$\mathrm{CAD} / \mathrm{CAM}$ ceramics are available in blocks or discs of different sizes, colors, optical features and sintered stage. These blocks or discs are grinded/milled with diamonds burs or metal cutters to the desired shape of the restoration - this is called subtractive machining process. Based on sintered stage of block, the manufacturing can be divided into soft or hard machining. Presently CAD/CAM machining materials can be categorized as:

- Glass ceramics: Feldspar ceramics mainly containing silica

- Glass ceramics reinforced with crystals: Leucite reinforced ceramics, Lithium disilicate ceramics, Zirconia reinforced lithium disilicate ceramics

- Polycrystalline ceramics: Zirconia ceramics which consist only in a crystalline matrix [8]

- PICN- Polymer infiltrated ceramics network

\section{Feldspar ceramics}

The feldspar ceramics for CAD/CAM use are made from a similar material as traditional feldspar ceramics but by different process, called extrusion molding, to achieve the desired blocks or discs shape [9]. For example, Vita Mark II (Vita Zahnfabrik) consists of 30\% fine grinded ground feldspar particles. The average size of the particles is 4 micrometers [10-12]. In the feldspar ceramics the leucite crystals arise due to firing process when the feldspar is melting. Leucite crystals have a very similar diffraction index as glass matrix. For this reason, restorations made from this ceramic can have a good esthetic result due to their translucent properties [13].

Figure 1 depicts the range of flexural strength measured by the three point bending test [10,12,14-22], figure 2 shows the range of elastic modulus [15,20,23-26] and figure 3 demonstrates the range fracture toughness $[9,15,20,22,27]$ of feldspar ceramics (Vita Mark II).

The indications for this type of ceramic are: inlay, onlay, veneer, partial crown, anterior crown, and veneering material for oxide ceramic substrate $[22,25,28,29]$. The main advantages are esthetics, translucency, wide range of block shades, while the disadvantages include fragility and translucency [23].

The ceramics are grinded in a fully sintered stage (hard machining). Cooling water is used to protect overheating of the grinding material $[9,30]$. The restoration can be finally treated by polish, glaze, stains or personalized with cut back technique [23]. Due to the high content of ceramics and poor mechanical properties, this ceramic material is recommended to be fixed by adhesive fixation to increase the restoration resistance to fracture [31].

Examples of representative CAD/CAM ceramics that can be found on the market are Vita Mark II (Vita Zahnfabrik), Cerec blocs (Sirona Dental Systems), Vita TriLuxe forte (Vita Zahnfabrik), Vita RealLife (Vita Zahnfabrik).

Leucite reinforced glass ceramics

The leucite glass ceramics consists of leucite crystals and glass matrix. For example, IPS Empress CAD (Ivoclar -Vivadent) is 30-45\% represented by leucite crystals (KAlSi2O6) which are approximately 1-10 micrometers in diameter $[3,9,32]$. Leucite crystals influence the thermal expansion of material and eliminate the propagation of cracks if the fracture energy is absorbed by crystals. The difference between the thermal expansion of the crystals and the glass matrix causes an increase in resistance and flexural strength [29].

Figure 1 depicts the range of flexural strength values which were measured by three point bending test $[9,12,15,18,22,29,33]$, figure 2 shows range of elastic modulus [15,23,25,34$36]$ and figure 3 demonstrates the fracture toughness [15,22,34,36] of leucite reinforced glass ceramics (IPS Empress CAD).

Indications for leucite glass ceramics are: inlay, onlay, partial crown, veneer, and anterior crowns [22,28,29]. Their advantages include 
good aesthetics, translucency, wide range of block shades, while the disadvantages are mainly fragility and translucency [23].

The ceramics blocks are also present and grinded in fully sintered stage (hard machining) and cooled by water during the grinding process to protect overheating $[4,9,30]$. The final surface treatment is the same as for feldspar ceramics [23]. This ceramic has higher content of glass and the adhesive fixation is also recommended to increase the strength of final restoration [31].

Examples of representative $\mathrm{CAD} / \mathrm{CAM}$ ceramics on the market are IPS Empress CAD (Ivoclar -Vivadent); Initial LRF Block Universal (GC); Initial LRF Block CEREC/InLab Blocks (GC).

\section{Lithium disilicate glass ceramics}

Lithium disilicate glass ceramics appear on the market under the name IPS e.max CAD (Ivoclar-Vivadent). These ceramic provides good mechanical and esthetics properties. Lithium disilicate glass ceramics consists of 70 $\%$ lithium disilicate crystals (Li2SiO5) and retains relatively high translucency properties [9]. Translucency is achieved due to the low refractive index of lithium disilicate crystals [3]. Crystals dimensions are 1.5-5 micrometers $[9,13]$. The large amount of crystals help to increase the strength [29]. IPS e.max CAD is produced in partially crystallized stage and is called blue stage because of the color of partially crystallized block of ceramic. Blue stage consists of $40 \%$ of the meta-silicates crystals (Li2SiO3), around 0.2-1 micrometers in diameter. This composition enables easier milling and less deterioration of grinding tools. The restoration after milling is still in the partially crystalline state and has to undergo a crystallization process. During this process, the meta-silicate crystals are dissolved and the lithium disilicate crystals are crystalized. After the crystallization process, the ceramics obtain the shade, translucency, and the mechanical features described above $[9,10,37,38]$.

Figure 1 depicts the range of flexural strength measured by the three point bending test $[9-13,17,18,22,25,33,39-43]$, figure 2 demonstrates range of elastic modulus $[23,25,26,34,35,39,42-46]$ and figure 3 shows the fracture toughness $[22,25,27,34,40-47]$ of lithium disilicate glass ceramics in fully crystallized stage (IPS e.max CAD).

These ceramics are sold in a fully sintered, partially crystalized stage [4]. After the hard milling by water cooling, the restoration needs to undergo the crystallization process to achieve final crystallinity, strength and optical features. The final surface treatment for monolithic restoration includes polishing, staining, glazing or cut back technique, and the restoration can also be veneered with conventional ceramic [23]. Both cementation types (conventional/adhesive) are reported, but to maximize strength, adhesive cementation is usually preferred to reinforce the present ceramics $[11,30,48,49]$.

Suitable indications for Lithium disilicate glass ceramics are: inlay, onlay, veneer, partial crown, anterior and posterior crown [29], endocrowns [23], three-unit bridges up to premolar, anterior and posterior implant abutments and implant crowns, and veneering material $[22,28]$. The main advantages include good aesthetics, mechanical strength, wide range of block shades and good optical properties. The disadvantage of lithium disilicate ceramics is usually low translucency [23].

Example representatives are IPS e.max CAD (Ivoclar-Vivadent); Amber Mill (Hass); Obsidian (Glidewell Laboratories); Suprême.cad (Suprême); Rosetta SM (Hass); MAZIC Claro CAD (Vericom).

Lithium di-silicate ceramics reinforced with zirconia

New lithium disilicate ceramics reinforced with zirconia are appearing on the market. Lithium di-silicate ceramics reinforced with zirconia consist of a fine-grain crystalline phase of lithium metasilicate and lithium disilicate with an average size of crystals being about 0.50.7 micrometers. These lithium disilicate ceramics are reinforced with $8-10 \mathrm{wt} \%$ of zirconia which is dissolved in glass matrix [37,39,49-51]. This results in higher flexural strength. An example of the lithium disilicate zirconia ceramics on the market is the Vita Suprinity (Vita Zahnfabrik). This material is sold in the partially crystallized form, so it is easier to mill the restoration [37]. 
Figure 1 shows range of flexural strength values measured by the three point bending test $[12,14,25,33,42-44]$, figure 2 refers to the range of elastic modulus [25,42-46] and figure 3 depicts range of fracture toughness [25,4246,52] of zirconia reinforced lithium disilicate glass ceramic in fully crystallized stage (Vita Suprinity).

Lithium disilicate zirconia reinforced ceramics is sold in fully sintered partially/fully crystalized state. After water-cooled hard machining, the restoration in partially crystalized state has to undergo thermal heating process called crystallization. During this thermal process, the ceramic will reach final crystallization and increase in strength. Final surface treatment is identical to the lithium disilicate ceramics [23]. The adhesive fixation is recommended $[49,50]$.

The types of restorations which can be indicated for Lithium disilicate zirconia reinforced ceramics are veneers, inlays, onlays, anterior and posterior crowns [29], endocrowns, bridges of small extent in anterior region [23]. The advantages of this ceramics are good esthetics, mechanical strength, wide range of blocks shades and their optical properties. The disadvantage is typically less translucency [23]. Available products on the market are Vita Suprinity (Vita Zahnfabrik); Celtra Duo (Sirona Densply). Celtra Duo is sold in fully crystallized form.

\section{Zirconia ceramics}

Zirconia is a polycrystalline ceramic. It is a highly crystalline ceramic without an intervening matrix. Chemically it is zirconium dioxide [13]. Zirconia is available in three crystalline forms: monoclinic, tetragonal and cubic. The monoclinic form is stable from room temperature to $1170^{\circ} \mathrm{C}$ and the density is $5.6 \mathrm{~g} / \mathrm{cm}^{2}$. Tetragonal phase is stable from $1170^{\circ} \mathrm{C}$ to $2370^{\circ} \mathrm{C}$. This form has good mechanical properties with density of 6.1 $\mathrm{g} / \mathrm{cm}^{2}$. The cubic phase is stable at over $2370^{\circ} \mathrm{C}$ and its density is $6.27 \mathrm{~g} / \mathrm{cm}^{2}$. Due to the low mechanical properties of the monoclinic phase, it is good to eliminate this phase in the composition of the ceramics $[9,53]$. Tetragonal/cubic zirconia can be partially stabilized in room temperature by adding an oxide such as yttria (Y2O3), ceria (CeO2) or magnesia $(\mathrm{MgO})[4,9]$.

Zirconia ceramics have a unique feature called transformation toughening. Transformation toughening occurs when the propagation of the crack induces the stress which results in a phase change from tetragonal phase to monoclinic phase. Due to this phase transformation, there is a volume increase of 3$5 \%$ which results in compressive stress around the walls of the crack. This closes the crack in transformation zone, decreases crack propagation and increases the toughness of material $[4,13]$.

The manufacture of zirconia restorations can be divided to soft machining process, hard machining manufacture [4]. The zirconia blocks or discs for CAD/CAM technique are sold in three states: chalk or green state (nonsintered), pre-sintered or fully sintered state [5].

The not fully sintered states are softer and easier for milling. This causes less wear of milling burs. Milling of non-sintered and presintered blocks is called soft machining process and has to be followed by sintering process. The green stage is very porous and could absorb a lot of water, thus, dry milling is required to avoid drying time before sintering. The restorations from non-sintered and presintered zirconia ceramics are milled in a larger sizes to allow for a shrinkage during the sintering process (about 20-25\%) [23,30,53]. The fully crystalized blocks are manufactured by grinding with diamonds burs with water cooling. The disadvantages of hard machining process of fully crystalized blocks are higher wear of grinding burs and longer grinding time. The advantage is the non-shrinkage of the material [30].

The fixation of zirconia ceramic is mostly done with conventional cementation, but adhesive fixation of zirconia ceramic is also possible. The zirconia is not etchable by hydrofluoric acid due to the absence of glass nor contain silica to achieve chemical bond with silane coupling agent. To achieve micro retention, air abrasion with alumina particle or tribochemical silica coating is used to increase surface roughness. Then the surface is treated with adhesive with MDP monomer (methacryloyloxydecyl dihydrogen phosphate monomer) to achieve chemical bond between 
dental surface and resin cement. If the surface is air abraded with silica coated alumina particles, the surface can be treated with the silane coupling agents for glass ceramics $[31,54]$.

\section{Y-TZP zirconia}

The 3Y-TZP (yttria tetragonal zirconia polycrystals) frameworks are very opaque due to the high content of alumina. The monolithic form requires veneering with glass ceramics to achieve an improved esthetic result [55]. The manufactures later introduced a dedicated monolithic zirconia, having lower content of alumina which increases translucency, but is still quite opaque compared to glass ceramic. 3Y-TZP is commonly stabilized with $3 \mathrm{~mol} \%$ of yttria [3Y-TZP] and the tetragonal phase is stabilized at room temperature. Both forms exhibit transformation toughening.

The mechanical properties of these forms are similar [23,46,53,53]. Zirconia causes wear of the antagonist enamel that can be improved with a surface finishing and polishing technique [55]. Figure 1 depicts the range of flexural strength measured by three point bending test $[12,18,43,46,53,56]$, the range of elastic modulus is shown in figure $2[15,43,56]$ and figure 3 shows the fracture toughness $[15,34,43,46,57]$ of $3 Y-T Z P$ ceramics. Since the mechanical properties for 3Y-TZP zirconia are predominantly reported for a whole group rather than for individual brands of this material, the mechanical properties for the whole group are shown here.

Suitable indication for restorations from 3Y-TZP ceramics are crowns, bridges, implants abutments, implants, orthodontic brackets, endodontics posts [9]. The advantages of 3Y-TZP ceramic are its mechanical properties, while the disadvantages include worse aesthetics, less translucency and implementation [23] and antagonist wear [55].

Examples of representative CAD/CAM ceramics on market are: Framework zirconia Vita YZ T (Vita Zahnfabrick); In-Ceram Classic Zirconia (VITA North America); In-Ceram YZ (VITA North America); inCoris ZI (Dentsply Sirona); IPS E.max ZirCad LT MO (Ivoclar Vivadent). Monolytic zirconia - IPS E.max ZirCad LT (Ivoclar Vivadent); Lava Plus (3M ESPE); Katana HT,
ML (Kuraray Noritake); Cercon HT (Dentsply Sirona); Vita YZ HT (Vita Zahnfabrick); inCoris TZI, TZI C (Dentsply Sirona); BruxZir Full-Strength (Glidewell Laboratories); Pretau Zirconia (Zirkonzahn).

\section{Cubic zirconia}

Currently, a more translucent zirconia form is available on the market, namely cubic zirconia or 4Y-TZP/5Y-TZP (yttria stabilized zirconia) zirconia. It is zirconia stabilized with 4 or $5 \%$ yttria and contains a higher percent of cubic phase. $4 Y-T Z P$ contains more than $25 \%$ of cubic phase and 5 Y-TZP zirconia up to 50 $\%$ of cubic phase. This increases the translucency of the material $[23,43,58]$. The translucency is also achieved by reduction of light scattering due to larger size of grains and less grains boundaries. The size of the grains is around $1.5 \mu \mathrm{m}$ while $3 \mathrm{Y}$-TZP has size of grains around $(0.5-1 \mu \mathrm{m}) \quad[23,43]$. The main disadvantages of these materials are that they have smaller amount of tetragonal phase and the cubic phase does not undergo transformation toughening [58]. Thus, the mechanical features such as strength and toughness decrease in comparison with conventional zirconia. The flexural strength is denoted around 500 to $700 \mathrm{MPa}$ [43]. Suitable indications for this ceramic material are veneer, inlay, onlay [43], single crown and anterior three-unit bridge [58]. The advantages can include esthetics, higher translucency in comparison with conventional zirconia and the disadvantages are low mechanical properties.

There are very few experimental measurements of the mechanical properties of the new zirconia, thus they were not included in the graphs. Examples of representative CAD/CAM ceramics on market can be $4 \mathrm{Y}$ TZP- IPS e.max ZirCAD MT (Ivoclar Vivadent); Katana ST/STML; Zpex 4 (Tosoh). 5Y-TZP: Lava esthetics (3M ESPE); Katana UT/UTML (Kuraray Noritake); BruxZir Anterior (Glidewell Laboratories); Pretau Anterior (Zirkonzahn); Zpex Smile (Tosoh).

Polymer Infiltrated ceramic network (PICN)

PICN is ceramic network which is infiltrated by polymer. It contains ceramic $(75$ $\% \mathrm{v} / \mathrm{v}, 86 \% \mathrm{w} / \mathrm{w})$ and polymer $(25 \%$ of $\mathrm{v} / \mathrm{v}$, $14 \% \mathrm{w} / \mathrm{w})[10,22,37,59]$. This ceramic mostly 
contains $23 \%$ alumina and polymer and is composed mainly of TEGDMA (triethylene glycol dimethacrylate) and UDMA (urethane dimethacrylate). Due to the added polymer in the ceramics, the hybrid ceramics are less hard than traditional ceramics and therefore cause less antagonist wear. Therefore the material lost over time is higher in comparison with traditional ceramic [60]. The flexural strength, elasticity and abrasion are very similar to dentin [61].

Figure 1 depicts the range of flexural strength values measured by the three point bending test $[10,14,19,21,22,25,37,39,40]$, the range of elastic modulus is shown on figure 2 [23-25,39,40,62,63] and figure 3 demonstrate range of fracture toughness [22,27,40,62,63] of PICN (Vita Enamic - Vita Zahnfabrik).

The final surface is polished to high gloss and the restoration can be also individualized by staining. Manufacturers denote adhesive fixation, including hydrofluoric acid etching of inner- surface and application of silane coupling agent.

Inlay, onlay, veneer, anterior and posterior crown can be made from these type of ceramics $[22,28,29]$. The advantages of PICN are the mechanical properties, rapid milling, implementation and low antagonists' wear. Disadvantages can be less aesthetics and sustainability [23].

\section{Flexural strength}

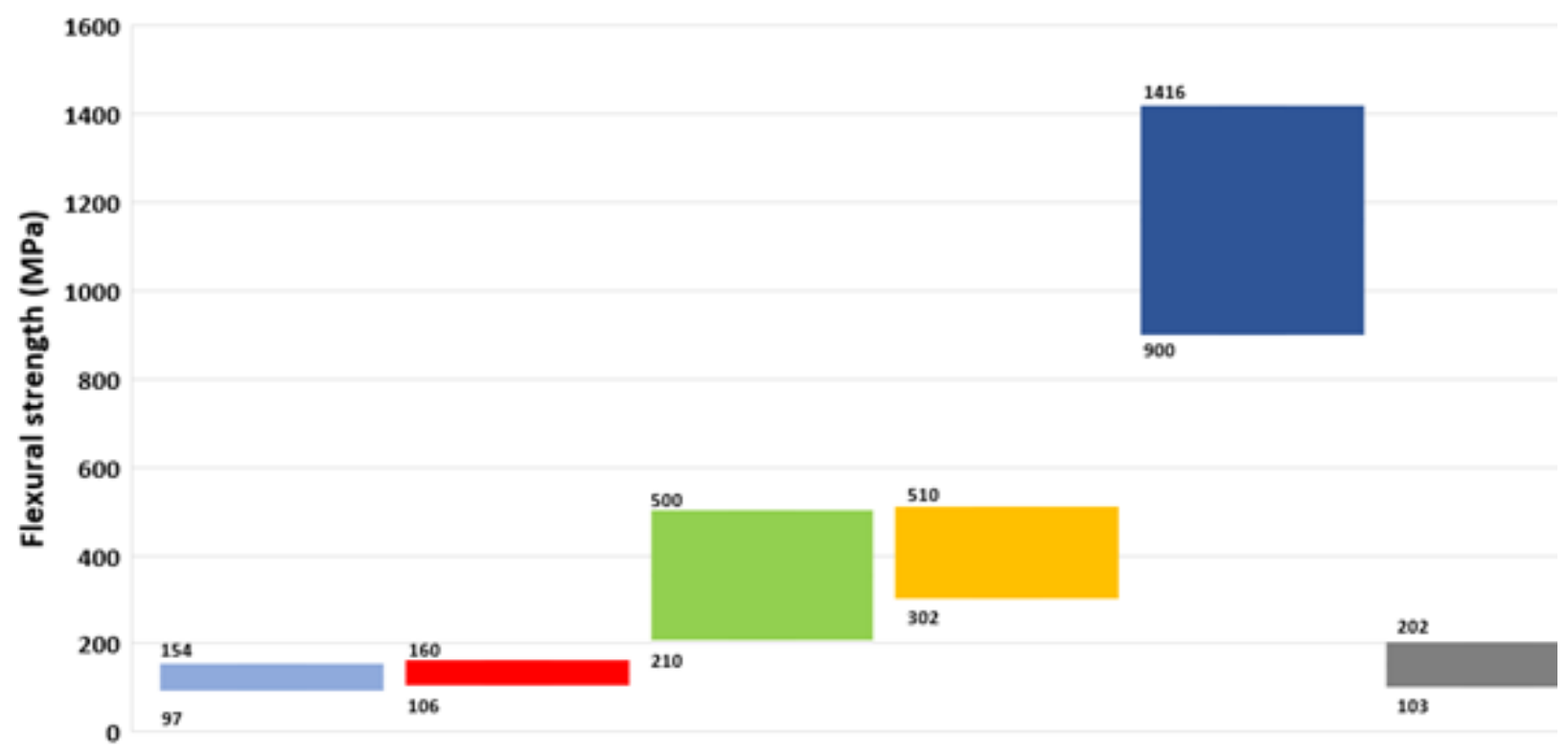

" vita Mark II $=$ IPS Empress CAD $=$ IPS e.max CAD $=$ Vita Suprinity $=3$ -

Figure 1. Flexural Strength. Boxing graph shows the range of flexural strength in MPa for each ceramic group. 


\section{Elastic modulus}

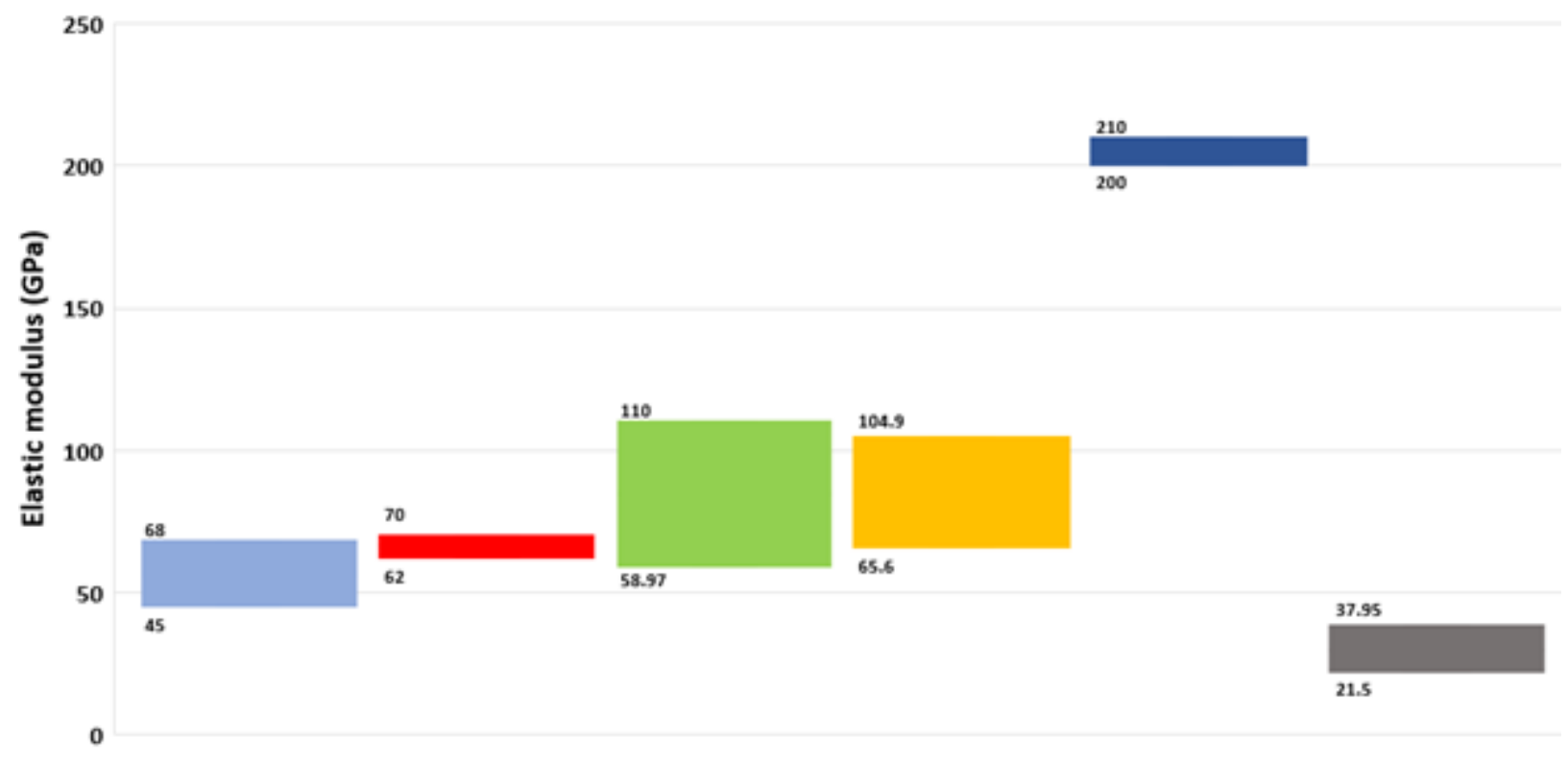

" Vita Mark II = IPS Empress CAD =IPS e.max CAD $=$ Vita Suprinity = 3Y-TZP $\mid$ Enamic

Figure 2. Elastic Modulus. The boxing graph shows the range of elastics modulus in GPa for each ceramic group.

\section{Fracture Toughness}

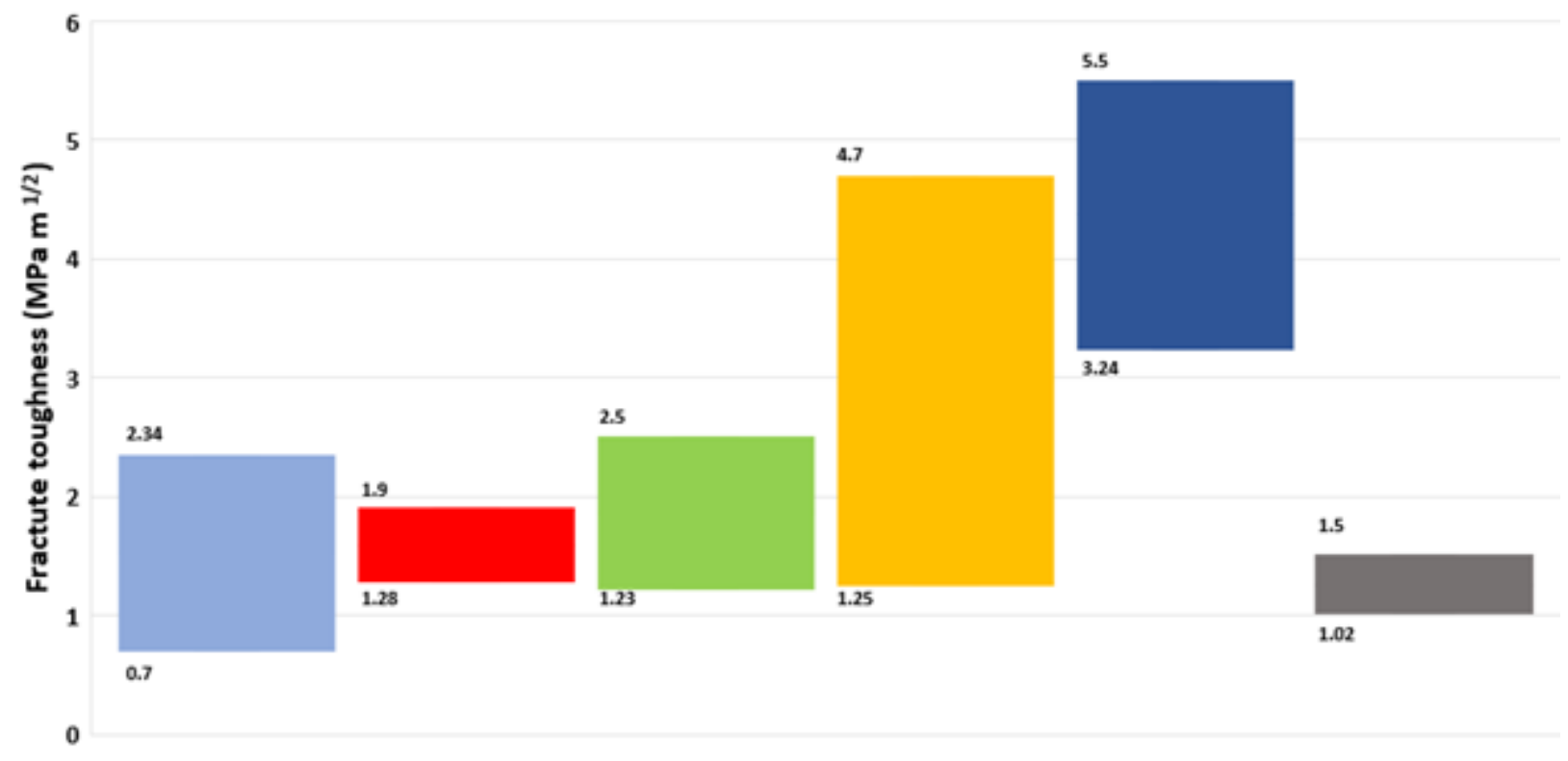

" Vita Mark II = IPS Empress CAD = IPS e.max CAD = Vita Suprinity = 3Y-TZP = Enamic

Figure 3. Fracture Toughness. The boxing graph shows the range of fracture toughness in MPam ${ }^{1 / 2}$ for each ceramic group.

\section{Discussion}

As could be seen in Figures 1-3, zirconia ceramic 3Y-TZP has the highest values of all the mentioned mechanical properties: flexural strength (900-1416 MPa); elastic modulus (200-210 GPa) and fracture toughness (3.24$\left.5.5 \mathrm{MPam}^{1 / 2}\right)$.
The lowest values of flexural strength (97$154 \mathrm{MPa}$ ) and fracture toughness (0.7-2.34 $\mathrm{MPam}^{1 / 2}$ ) are shown with Vita Mark II. This is likely due to the highest amount of glass in its composition. The lowest value of elastic modulus is reported for Vita Enamic (21.5$37.95 \mathrm{GPa}$ ). This is in line with the statement from Ceren at al. that elastic modulus of Vita 
Enamic exhibits the similar properties as dental tissues.

Vita Enamic has likely the closest elastic modulus to dentin which is likely due to the added polymer. It is still controversial topic amongst dentists whether PICN and nanoceramics should be classified as ceramics. In PICN the matrix reinforced by polymer is ceramics, but in resin nanoceramic the matrix reinforced by ceramic is polymer, therefore PICN should be considered a ceramic, but the resin nanoceramics should not. PICN is also sometimes classified as hybrid ceramic. Some authors and manufactures include resin nanoceramic in the hybrid ceramics. Since this brings even more confusion, we referred to PICN hybrid as a ceramic.

For feldspar ceramic and leucite reinforced ceramic the use for crowns in posterior region is not indicated due to deficient mechanical characteristics to resist the loading from posterior chewing forces.

The ratio of crystals and glass composition influence the mechanical and optical properties of ceramic material. Based on the presented information, one can conclude that if the ceramics predominantly consists of glass matrix, the resulting restoration will be more translucent with good aesthetic but weaker. If the ceramics consists predominantly of crystals, the resulting restoration will have very good mechanical properties but will be opaquer. It follows that crystals increase the mechanical resistance and glass matrix adds aesthetics and a potentially a more natural look for a ceramic restoration. Nevertheless, it was shown that transmission of light through the material can also be influenced by the size of crystals, quantity of crystals, crystalline phase, pigments and wavelength and thus influence the translucency of the ceramic material [64].

The clinician has to also keep in mind the fatigue of the material. The strength values from three-point bending test denote the maximum stress when the material is exposed to a single load. The ceramic restorations are subjected in the mouth to the cyclic loads several times a day during the chewing process. If the ceramic material is loaded several times under the yield point (the point where plastic deformation of material occurs), it can cause the fatigue of ceramic material. This means that the material strength reduces, and this can lead to a failure of the material. The fatigue of material can be also influenced by other condition in patient mouth such as $\mathrm{pH}$ changes, humidity and thermal changes [4].

\section{Conclusion}

There are various CAD/CAM ceramic groups which have different mechanic and aesthetic properties. The clinician should identify the differences between these ceramics in order to be able to choose properly the suitable material for each individual case.

\section{Conflict of interest: None declared}

\section{References}

1. Tin-Oo MM, Saddki N, Hassan N. Factors influencing patient satisfaction with dental appearance and treatments they desire to improve aesthetics. BMC Oral Health. 2011;11(1):1-8.

2. Samorodnitzky-Naveh GR, Geiger SB, Levin L. Patients' satisfaction with dental esthetics. The Journal of the American Dental Association. 2007;138(6):805-8.

3. McLaren EA, Giordano R. Ceramics overview: classification by microstructure and processing methods. International Dentistry - African Edition. 2014;4(3):18-30.

4. Sakaguchi, Powers. Craig's Restorative dental materials. Edition thirteen. Elsevier Mosby; 2012. P.33-49; 85; 91; 253-258.

5. Anusavice K, Shen C, Rawls R. Philip's Science od Dental Materials. Edition twelve. Elsevier; 2013.P. 48-64.

6. Domingues NB, Galvão BR, Ribeiro S, Almeida Junior AA de, Longhini D, Adabo GL. Comparison of the indentation strength and single-edge- $v$ notched beam methods for dental ceramic fracture toughness testing. Braz J Oral Sci. 2017;15(2):109-112.

7. Chun KJ, Lee JY. Comparative study of mechanical properties of dental restorative materials and dental hard tissues in compressive loads. Journal of Dental Biomechanics. 2014;5:1-6.

8. Shenoy A, Shenoy N. Dental ceramics: An update. J Conserv Dent. 2010;13(4):195-203.

9. Li RWK, Chow TW, Matinlinna JP. Ceramic dental biomaterials and CAD/CAM technology: State of the art. Journal of Prosthodontic Research. 2014;58(4):208-16.

10. Leung BTW, Tsoi JKH, Matinlinna JP, Pow EHN. Comparison of mechanical properties of three machinable ceramics with an experimental 
fluorophlogopite glass ceramic. The Journal of Prosthetic Dentistry. 2015;114(3):440-6.

11. Fasbinder DJ. Materials for Chairside CAD/CAM Restorations. Compendium of continuing education in dentistry. 2010;31(9):702-9.

12. Atay DDS, PhD A, Sağirkaya DDS, PhD E. Effects of Different Storage Conditions on Mechanical Properties of CAD/CAM Restorative Materials. Odovtos - Int J Dent Sc. 2019;161-74.

13. Helvey GA. Classification of Dental Ceramics. Inside dentistry. 2013;April 2013:62-76.

14. Sen N, Us YO. Mechanical and optical properties of monolithic CAD-CAM restorative materials. The Journal of Prosthetic Dentistry. 2018;119(4):5939.

15. Low IM. Advances in Ceramic Matrix Composites. Edition secound. Woodhead publishing; 2018. P.711-721.

16. Vichi A, Sedda M, Del Siena F, Louca C, Ferrari M. Flexural resistance of Cerec CAD/CAM system ceramic blocks. Part 1: Chairside materials. American Journal of Dentistry. 2013;26(5):255-9.

17. D'Arcangelo C, Vanini L, Rondoni GD, De Angelis F. Wear properties of dental ceramics and porcelains compared with human enamel. The Journal of Prosthetic Dentistry. 2016;115(3):350-5.

18. Denry I, Holloway J. Ceramics for Dental Applications: A Review. Materials. 2010;3(1):35168.

19. Blackburn C, Rask H, Awada A. Mechanical properties of resin-ceramic CAD-CAM materials after accelerated aging. The Journal of Prosthetic Dentistry. 2018;119(6):954-8.

20. Lu T, Peng L, Xiong F, et al. A 3-year clinical evaluation of endodontically treated posterior teeth restored with two different materials using the CEREC AC chair-side system. The Journal of Prosthetic Dentistry. 2018;119(3):363-8.

21. Lauvahutanon S, Takahashi $H$, Shiozawa $M$, et al. Mechanical properties of composite resin blocks for CAD/CAM. Dent Mater J. 2014;33(5):705-10.

22. Sonmez N, Gultekin P, Turp V, Akgungor G, Sen D, Mijiritsky E. Evaluation of five CAD/CAM materials by microstructural characterization and mechanical tests: a comparative in vitro study. BMC Oral Health. 2018;18(5):1-13.

23. Lambert H, Durand J-C, Jacquot B, Fages M. Dental biomaterials for chairside CAD/CAM: State of the art. J Adv Prosthodont. 2017;9:486-95.

24. Alamoush RA, Silikas N, Salim NA, Al-Nasrawi S, Satterthwaite JD. Effect of the Composition of CAD/CAM Composite Blocks on Mechanical Properties. BioMed Research International. 2018;2018:1-8.

25. Sulaiman TA. Materials in digital dentistry-A review. J Esthet Restor Dent. 2020;32(2):171-81.
26. de Kok P, de Jager N, Veerman IAM, Hafeez N, Kleverlaan CJ, Roeters JFM. Effect of a retention groove on the shear bond strength of dentinbonded restorations. The Journal of Prosthetic Dentistry. 2016;116(3):382-8.

27. Badawy R, El-Mowafy O, Tam L. Fracture toughness of chairside CAD/CAM materials Alternative loading approach for compact tension test. Dental Materials. 2016;32:847-52.

28. Bajraktarova-Valjakova E, Korunoska-Stevkovska V, Kapusevska B, Gigovski N, Bajraktarova-Misevska C, Grozdanov A. Contemporary Dental Ceramic Materials, A Review: Chemical Composition, Physical and Mechanical Properties, Indications for Use. Open Access Maced J Med Sci. 2018;6(9):1742-55.

29. Sannino G, Germano F, Arcuri L, Bigelli E, Arcuri C, Barlattani A. Cerec CAD/CAM chairside system. Oral \& Implantology. 2014;7(3):57-70.

30. Beuer F, Schweiger J, Edelhoff D. Digital dentistry: an overview of recent developments for CAD/CAM generated restorations. $\mathrm{Br}$ Dent J. 2008;204(9):505-11.

31. Vargas MA, Bergeron C, Diaz-Arnold A. Cementing all-ceramic restorations. The Journal of the American Dental Association. 2011;142:20S-24S.

32. Brenes DC, Duqum I, Mendonza G. Materials and systems for all c-eramic CAD/CAM restorations. Dental tribute. 2016;3:10-5.

33. Pitiaumnuaysap $L$, Phokhinchatchanan $P$, Suputtamongkol K, Kanchanavasita W. Fracture resistance of four dental computer-aided design and computer-aided manufacturing glassceramics. Mahidol Dental Journal. 2017;37(2):201-8.

34. Ritzberger C, Apel E, Höland W, Peschke A, Rheinberger $V$. Properties and Clinical Application of Three Types of Dental Glass-Ceramics and Ceramics for CAD-CAM Technologies. Materials. 2010;3(6):3700-13.

35. Zhu J, Rong Q, Wang X, Gao X. Influence of remaining tooth structure and restorative material type on stress distribution in endodontically treated maxillary premolars: A finite element analysis. The Journal of Prosthetic Dentistry. 2017;117(5):646-55.

36. Byeon S-M, Song J-J. Mechanical Properties and Microstructure of the Leucite-Reinforced GlassCeramics for Dental CAD/CAM. J Dent Hyg Sci. 2018;18(1):42-9.

37. Furtado de Mendonca A, Shahmoradi M, Gouvêa CVD de, De Souza GM, Ellakwa A. Microstructural and Mechanical Characterization of CAD/CAM Materials for Monolithic Dental Restorations: Characterization of CAD/CAM Materials. Journal of Prosthodontics. 2019;28(2):587-94. 
38. Culp L, McLaren EA. Lithium Disilicate: The Restorative Material of Multiple Options. Compendium of continuing education in dentistry. 2010;31(9):716-25.

39. Lawson NC, Bansal R, Burgess JO. Wear, strength, modulus and hardness of CAD/CAM restorative materials. Dental Materials. 2016;32(11):275-83.

40. Goujat A, Abouelleil H, Colon P, Jeannin C, Pradelle $N$, Seux D, et al. Mechanical properties and internal fit of 4 CAD-CAM block materials. The Journal of Prosthetic Dentistry. 2018;119(3):384-9.

41. Zarone F, Ferrari M, Mangano FG, Leone R, Sorrentino R. "Digitally Oriented Materials": Focus on Lithium Disilicate Ceramics. International Journal of Dentistry. 2016;2016:1-10.

42. Elsaka SE, Elnaghy AM. Mechanical properties of zirconia reinforced lithium silicate glass-ceramic. Dental Materials. 2016;32(7):908-14.

43. Zhang Y, Lawn BR. Novel Zirconia Materials in Dentistry. Journal of Dental Research. 2018;97(2):140-147.

44. Chen X-P, Xiang Z-X, Song X-F, Yin L. Machinability: Zirconia-reinforced lithium silicate glass ceramic versus lithium disilicate glass ceramic. Journal of the Mechanical Behavior of Biomedical Materials. 2020;101:1-10.

45. Ramos N de C, Campos TMB. Microstructure characterization and SCG of newly engineered dental ceramics. Dental Materials. 2016;32(7):870-8.

46. Sacher E, Franca R. Dental Biomaterials. Vol. secound. New Jersey: World Scientific; 2018. P.148-203.

47. Willard A, Gabriel Chu T-M. The science and application of IPS e.Max dental ceramic. The Kaohsiung Journal of Medical Sciences. 2018;34(4):238-42.

48. Eakle WS, Bastin KG. Dental Materials Clinical Applications for Dental Assistants and Dental Hygienists. fourth. Elsevier Health Sciences; 2019.

49. McLaren EA, Figueira J. Updating Classifications of Ceramic Dental Materials: A Guide to Material Selection. Compendium of continuing education in dentistry. 2015;36(6):739-44.

50. Rinke S, Rödiger M, Ziebolz D, Schmidt A-K. Fabrication of Zirconia-Reinforced Lithium Silicate Ceramic Restorations Using a Complete Digital Workflow. Case Reports in Dentistry. 2015;1-7.

51. Rinke S, Pabel A-K, Rödiger M, Ziebolz D. Chairside Fabrication of an All-Ceramic Partial Crown Using a Zirconia-Reinforced Lithium Silicate Ceramic. Case Reports in Dentistry. 2016;1-7.
52. Traini $T$, Sinjari B, Pascetta $R$, et al. The zirconiareinforced lithium silicate ceramic: lights and shadows of a new material. Dental Materials Journal. 2016;35(5):748-55.

53. Helvey GA. Zirconia and Computer-aided Design/Computer-aided Manufacturing (CAD/CAM) Dentistry. Inside dentistry. 2008;4(4).

54. Della Bona A, Borba M, Benetti $P$, et al. Adhesion to Dental Ceramics. Curr Oral Health Rep. 2014;1(4):232-8.

55. Passos SP, Torrealba Y, Major P, Linke B, Flores-Mir C, Nychka JA. In Vitro Wear Behavior of Zirconia Opposing Enamel: A Systematic Review: Enamel Wear Caused by Zirconia Ceramics. Journal of Prosthodontics. 2014;23(8):593-601.

56. Alghazzawi TF, Lemons J, Liu P-R, Essig ME, Bartolucci AA, Janowski GM. Influence of LowTemperature Environmental Exposure on the Mechanical Properties and Structural Stability of Dental Zirconia: Zirconia Exposed to LowTemperature Degradation. Journal of Prosthodontics. 2012;21(5):363-9.

57. Burgess JO. Zirconia: The Material, Its Evolution, and Composition. Compendium of continuing education in dentistry. 2018;39(4):4-8.

58. Meirelles L. Ceramic CAD/CAM Materials: An Overview of Clinical Uses and Considerations. ADA professional product rewiev. 2017;12(1):1-9.

59. Campos F, Almeida C, Rippe M, de Melo R, Valandro L, Bottino M. Resin Bonding to a Hybrid Ceramic: Effects of Surface Treatments and Aging. Operative Dentistry. 2015;40(6):1-8.

60. Ceren N, Turp V, Emir F, Akgungor G, Ayyildiz S, Şen D. Nanoceramics and hybrid

61. materials used in CAD/CAM systems. Aydın Dental Journal. 2016;55-61.

62. Dirxen C, Blunck U, Preissner S. Clinical Performance of a New Biomimetic Double Network Material. The Open Dentistry Journal. 2013;7:118-22.

63. Wang H, Cui B, Li J, et al. Mechanical properties and biocompatibility of polymer infiltrated sodium aluminum silicate restorative composites. J Adv Ceram. 2017;6(1):73-9.

64. Della Bona A, Corazza PH, Zhang Y. Characterization of a polymer-infiltrated ceramicnetwork material. Dental Materials. 2014;30(5):564-9.

65. Bao YW, Gong J, Tian. Testing and Evaluation of Inorganic Materials I. Switzerland: Trans Tech Publications Ltd; 2011. P.300. 
School of Dentistry, University of Alberta, 2J2.00 WC Mackenzie Health Sciences Centre 8440112 St. NW.

Edmonton, T6G 2R7, Alberta, Canada

Email: liran@ualberta.ca

Received: December 10, 2020 / Accepted: January 16, 2021 